\title{
Supporting Patient-Clinician Interaction in Chronic HIV Care: Design and Development of a Patient-Reported Outcomes Software Application
}

Susan Herrmann ${ }^{1}$, PhD; Brad Power ${ }^{2}$, BSc; Amineh Rashidi ${ }^{3}$, PhD; Mark Cypher ${ }^{2}$, PhD; Frank Mastaglia ${ }^{2}$, BCom; Amy Grace ${ }^{4}$, BPsych; Elizabeth McKinnon ${ }^{5}$, PhD; Pierre Sarrot ${ }^{6}$, MSc; Christophe Michau $^{7}$, MD; Matthew Skinner ${ }^{8}$, MBBS, FRACP; Renae Desai ${ }^{9}$, MBBS, MD, FRCP, FRACP; Martin Duracinsky ${ }^{6,10}$, MD, PhD

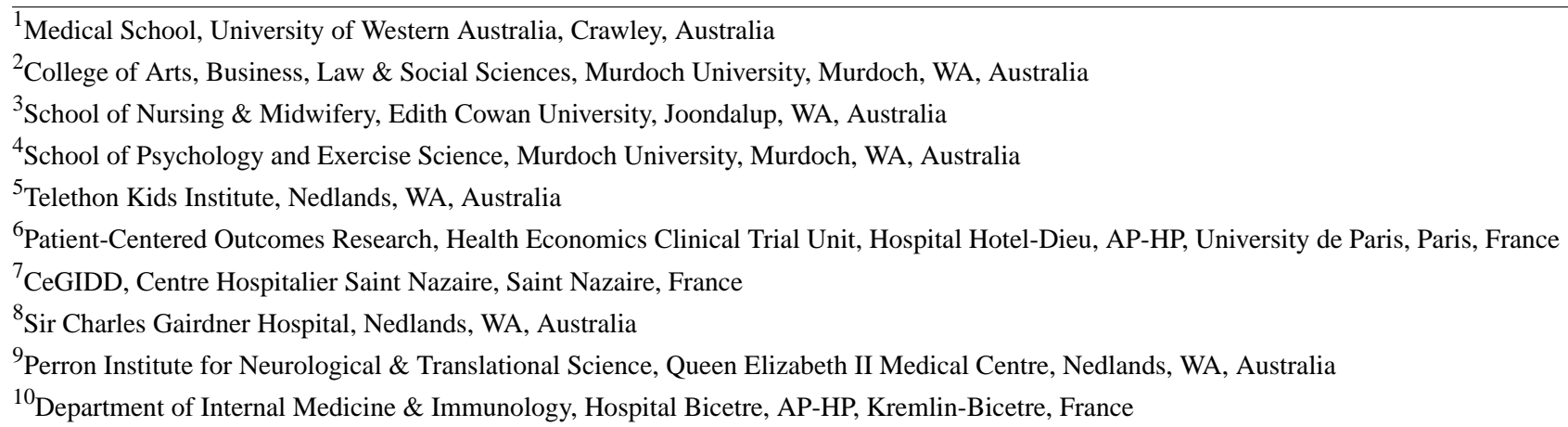

Corresponding Author:

Susan Herrmann, PhD

Medical School

University of Western Australia

35 Stirling Hwy

Crawley, 6009

Australia

Phone: 610417997934

Email: Susan.Herrmann@uwa.edu.au

\begin{abstract}
Background: The consideration of health-related quality of life (HRQL) is a hallmark of best practice in HIV care. Information technology offers an opportunity to more closely engage patients with chronic HIV infection in their long-term management and support a focus on HRQL. However, the implementation of patient-reported outcome (PRO) measures, such as HRQL in routine care, is challenged by the need to synthesize data generated by questionnaires, the complexity of collecting data between patient visits, and the integration of results into clinical decision-making processes.
\end{abstract}

Objective: Our aim is to design and pilot-test a multimedia software platform to overcome these challenges and provide a vehicle to increase focus on HRQL issues in HIV management.

Methods: A multidisciplinary team in France and Australia conducted the study with 120 patients and 16 doctors contributing to the design and development of the software. We used agile development principles, user-centered design, and qualitative research methods to develop and pilot the software platform. We developed a prototype application to determine the acceptability of the software and piloted the final version with 41 Australian and 19 French residents using 2 validated electronic questionnaires, the Depression, Anxiety and Stress Scale-21 Items, and the Patient Reported Outcomes Quality of Life-HIV.

Results: Testing of the prototype demonstrated that patients wanted an application that was intuitive and without excessive instruction, so it felt effortless to use, as well as secure and discreet. Clinicians wanted the PRO data synthesized, presented clearly and succinctly, and clinically actionable. Safety concerns for patients and clinicians included confidentiality, and the potential for breakdown in communication if insufficient user training was not provided. The final product, piloted with patients from both countries, showed that most respondents found the application easy to use and comprehend. The usability testing survey administered found that older Australians had reduced scores for understanding the visual interface $(P=.004)$ and finding the buttons organized $(P=.02)$. Three-fourths of the respondents were concerned with confidentiality $(P=.007)$, and this result was more prevalent in 
participants with higher anxiety and stress scores $(P=.01)$, as measured by the Depression, Anxiety and Stress Scale-21 Items. These statistical associations were not observed in 15 French patients who completed the same questionnaire.

Conclusions: Digital applications in health care should be safe and fit for purpose. Our software was acceptable to patients and shows potential to overcome some barriers to the implementation of PROs in routine care. The design of the clinicians' interface presents a solution to the problem of voluminous data, both synthesizing and providing a snapshot of longitudinal data. The next stage is to conduct a randomized controlled trial to determine whether patients experience increased satisfaction with care and whether doctors perceive that they deliver better clinical care without compromising efficiency.

(J Med Internet Res 2021;23(7):e27861) doi: 10.2196/27861

\section{KEYWORDS}

physician-patient communication; eHealth; primary care; ambulatory care; information systems; user-centered design; user context; patient reported outcomes; qualitative research; health care; HIV care; mobile phone

\section{Introduction}

\section{Background}

Chronic HIV infection is a complex disease associated with psychosocial morbidity that can affect health-related quality of life (HRQL) detrimentally [1]; however, as clinical management in primary care settings often focuses on physical well-being and the outcomes of antiretroviral therapy [1], psychosocial and other relevant patient-volunteered information may not be engaged in the same clinically systematic manner. Challenges to implementing patient-reported outcome (PRO) measurements in routine care include the synthesis of voluminous data generated by questionnaires regardless of whether they are e-questionnaires or paper based, the complexity of collecting data between patient visits, and the integration of the results into clinical decision-making protocols [2]. There are additional organizational barriers to integrating PRO measurement in real-life settings, in hospitals and at home, but guidance is available [3]; and obstacles have also been recognized in localized settings [4]. As some barriers become surmountable [2], there is an increased impetus in fields, such as HIV and oncology, to use validated measures for the assessment of physical and psychosocial symptoms and quality of life beyond the hospital setting and between patient visits [5-7]. Muessig et al [7] identified opportunities for digital health strategies to be integrated within the HIV Continuum of Care to aid retention. Those concerned with cancer care and trials have taken advantage of the advances in digital communications [8] to configure hospital computer systems and capture PRO data in real time to better reflect the patient experience [9] and facilitate intervention. Kjaer et al [10] described the hospital-based implementation of a web-based tool to facilitate the use of PROs in HIV care. They adapted AmbuFlex [11], a generic web-based program for the collection and synthesis of PRO data, envisaging that this platform could individualize patient care and inform targeted resource allocation, particularly with regard to the frequency of patient medical appointments. In the context of the current COVID-19 pandemic, reducing face-to-face encounters without compromising clinical outcomes is of current interest to both patients and health professionals [12]. However, although digital innovation may offer solutions to problems, new systems must be accepted and regarded as advantageous to patients and worthwhile for providers to implement successfully in clinical practice [13].

\section{Objectives}

We aim to develop a digital platform to facilitate the use of PROs in the context of chronic HIV infection. We believe that the meaningful engagement of health providers and patients, as equal stakeholders, will create a bidirectional incentive to use PRO software whereby "a common patient-centered frame of reference" [3] supports therapeutic communication and patient autonomy. Therefore, the digital communication package that we designed should reflect stakeholders' collective and differing requirements. We opted to use an iterative development process of agile design and qualitative research methods [14-16], in contrast with earlier approaches to software design that, in targeting potential users, tended to focus on technological capacity and maximum specification.

We envisaged the software to support the following communication process: patients would input information at home or in the clinic before their appointments using their own devices. The software then transmits the information to the medical practice software through a secure portal. Using a custom interface, doctors could review concise data from an automated, preprocessed synthesis of patient self-reports during patient consultation. The longitudinal information displayed graphically provides clinicians with trends over time. We set the following objectives: (1) to design a web-based application compatible with mobile and desktop, (2) to assess comprehension of the platform, and perceived benefits, (3) to assess the usability of the designed product, and (4) to conduct a pilot study using PRO instruments integrated into the platform. Our interdisciplinary Australian and French teams included medical, psychology, information technology (IT), and digital communications experts, and the study was conducted in both countries with the teams holding regular teleconferences over the course of the study.

\section{Methods}

\section{Study Design}

The study was observational and iterative, with each activity informing the next. In stage 1 , we created and tested a demonstration prototype or wireframe and assessed patient and clinician users' comprehension of the rationale behind the software. We then refined the design further, loaded the software with two validated PRO instruments, the Depression, Anxiety and Stress Scale (DASS-21) [17] and the Patient Reported 
Outcomes Quality of Life-HIV (PROQOL-HIV) HRQL instrument specific for HIV [18]; in stage 2, we initiated a pilot study. The project was conducted between December 2015 and May 2017, and the Murdoch University Human Research Ethics Committee (2015/228) and the French Ethics Committee Ile de France IV-Institutional Review Board 00003835 (2016/44NI) approved the study. The research was conducted in 3 hospitals in France and 2 specialist HIV practices in Western Australia (WA). Members of the research team with fluency in both languages carried out translations when necessary.

\section{Participants}

Participants were a sample of convenience and were eligible for the study if they were at least 18 years old and able to provide informed consent. All patients had been diagnosed with HIV infection and presented with a wide range of clinical and sociodemographic characteristics. Clinicians were trained either in infectious diseases or immunology, or were general practitioners with training in HIV medicine. Participants in stage 1 included patients with chronic HIV infection (Australian=4, French=36) and clinicians (Australian=4, French=12); those in stage 2 were patients (Australian=41, French=39) recruited from 3 hospitals in Paris and 2 community-based HIV specialist centers in WA. In addition, colleagues with various professional backgrounds, including clinicians, from within the 2 research organizations were asked to carry out the initial user testing of a basic prototype (stage 1).

\section{Data Analysis}

An interview guide was developed collaboratively. One-on-one face-to-face interviews, up to 45 minutes in length, were conducted in the study hospitals in France and at specialist practices in Australia. The interviews were recorded and transcribed. The transcripts were imported to NVivo 12 (QSR International Pty Ltd.) and analyzed independently by a male master's student, a female $\mathrm{PhD}$ student, and their $\mathrm{PhD}$ supervisors (SH, MD). An inductive thematic approach [19], informed by field data, was used to analyze the interview data. We coded text from the interviews to common themes and continued until the data were considered saturated [20]. Questionnaire data from the pilot study were exported and encrypted from the web application to the data capture program REDCap (Research Electronic Data Capture) [21] and subsequently downloaded into the software package $\mathrm{R}$ for quantitative analysis [22]. This included the derivation of descriptive summaries and the application of linear or logistic regression to explore associations with aspects of usability. Demographic information is presented as percentages or means, as appropriate.

\section{Stage 1: Design and Testing of the Initial Prototype}

To approach the design of the software, we implemented a user-centered design [23] and agile development principles $[14,15]$ that promote adaptive planning, evolutionary development, early delivery, and continuous improvement. This methodology provided increased transparency during the development phase through continuous feedback and flexibility when changes in direction were required. Our agile approach was informed by narratives, and as such, we educated the team on the lived patient experience of people affected by HIV by writing fictional personas informed by previous qualitative research [1].

The prototype consisted of basic functions, representing a minimum viable product. The architecture (Figure 1) comprises a web application that allowed qualitative instruments to be configured and patient accounts to be created. The instruments can then be deployed to client software applications that run on either mobile or desktop platforms and allow patients to provide responses to questionnaires. The client then submits the patient's response data via a secure channel back to the web application, where it is stored in a database. The doctors' interface was accessed through a web browser. This allows doctors and clinicians to access processed graphical reports of the scored patient responses to a PRO, identify longitudinal trends, and promote discussion with the patient. Finally, data export functionality allows the web application to export data in suitable formats for import into clinical patient management software. This architecture was implemented as a first pass to provide a minimum viable product for the initial testing.

We invited 20 colleagues, including clinicians, from both teams to use and comment on the software, which was configured with 10 testing items comprising questions and response categories. A member of the research team observed and recorded the users' verbal responses as they navigated the application and administered a short questionnaire. The data were collated as first round, in-house user testing to improve the usability of the prototype.

Figure 1. Diagram of communication between platforms.

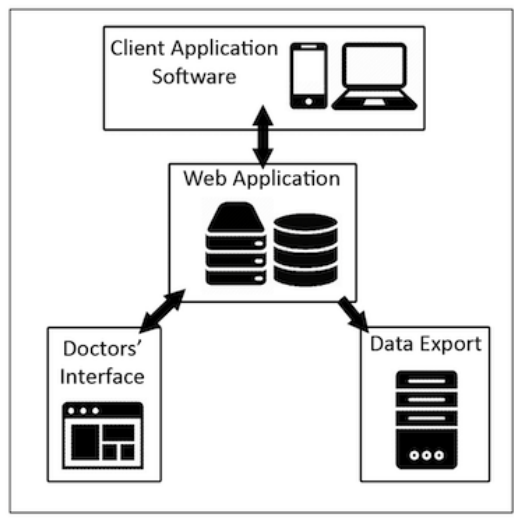




\section{Acceptability of the Concept}

Contemporaneously, we conducted 12 semidirected interviews of French patients to establish patients' perceptions on using health care-related software and the difference eHealth might make to their care. Other questions were related to the current style of communication between patients and clinicians and their experiences with electronic devices and mobile health (mHealth) apps.

\section{Testing of the Prototype}

The second round of user testing, comprising 44 semidirected interviews, took place in 3 Paris hospitals and 1 community-based clinic in WA. An interview guide was developed. In the first part of the interview, researchers described the purpose of the application and asked the patients $(n=28)$ and doctors $(n=16)$ about their computer usage habits and capabilities and their views on perceived benefits or harms of the software. They were then given an opportunity to view the application, and their reactions were noted [24]. Through this before-and-after approach, we were able to identify discrepancies between participants' expectations of the software and subsequent user experience.

\section{Graphic Design}

Informed by the fictional personae and predesign interviews, mood boards were created for colors, icons, and text (Multimedia Appendix 1). The initial design was for mobile devices such as smartphones, with the small screen presenting the greater design challenge regarding functionality. However, on a larger screen, there was no loss of function or esthetics (Figure 2). We used the composite data, empirical observations, previous research, and preliminary in-house user testing to create user stories, with short statements representing user requirements in French and English, which justified new features (Textbox 1). Each user story was coded to track the origin of the story from patient interview or empirical data (eg, "As a <stakeholder type> I want <some feature> so that <some benefit>"). Expressed in this way, it made the features easier to talk about and remember who they were for and to prioritize feature development. The stakeholders were patients, clinicians, researchers, and developers. The list of user stories informed a user story "backlog"-like a waiting room, ready to inform sprints that denoted a period of software development.

Figure 2. App design.

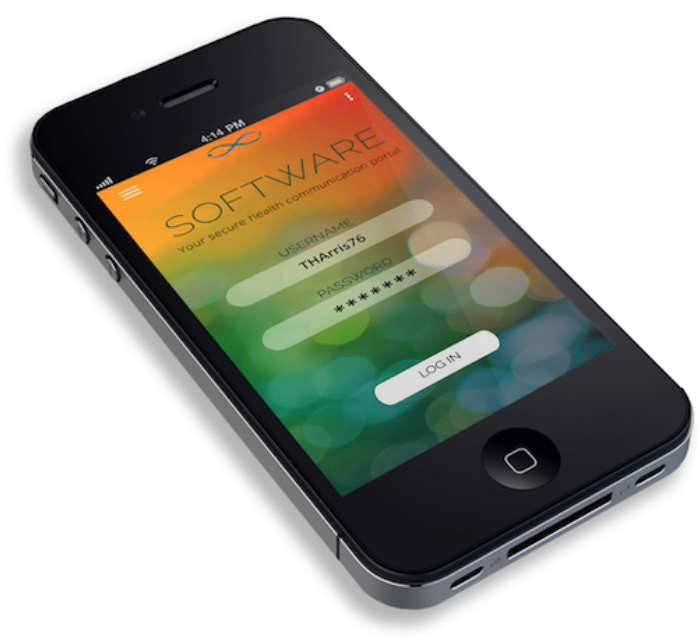

Textbox 1. User stories and sample quotes.

Sample Quotes

- "As a patient, I want to be in control of my data, and know it is secure and private, so that I can feel comfortable providing it."

- " "As a patient, I want this software available on the types of device(s) I own, so that it is accessible to me."

- "As a patient, I want clean, distraction free interaction with appropriate detail for fine control, so that my data are precise."

- " "As a patient, I want to use the software intuitively, without excessive instruction, so that it feels easy and effortless."

- "As a patient, I want a personalized experience, so that it does not feel like filling out a form."

- "As a doctor, I want clear and succinct results that inform a consultation, so that I do not get overwhelmed."

- " "As a doctor, I want unbiased results from the digital instruments, so that the patient reported outcomes are accurate."

\section{Design of the Clinician Interface}

In Australia, we interviewed 4 doctors, comprising 2 men and 2 women; 3 were from HIV specialist practices and 1 was hospital-based. We interviewed them before and after showing them the clinician interface (wireframe). The doctors were asked to envisage the utility of the software for measurement of HRQL and, informed by this feedback, the graphic artist refined the design of the interface (Figure 2). 


\section{Stage 2: Pilot Studies in Australia and France}

\section{Australia}

We recruited 41 Australians who were undergoing treatment for HIV infection from 2 high-case load community practices by the research nurse. After receiving minimal instruction and choosing a device (ie, desktop, laptop, tablet, or smartphone), they created an account and accessed the platform. Several participants preferred to use the software in their homes after phone contact with the researcher, but most accessed it in the clinic. The platform was configured using 4 questionnaires, including the 2 validated instruments: DASS-21 [17] and PROQOL-HIV [18,25]. The results of the 2 PROs are reported in this manuscript. Participants verbalized their experience while navigating the software to enable the researcher to note their observations, and they were instructed to record true responses. Participants also completed a usability questionnaire, and the researcher ranked the frequency of repetitive (similar) comments and provided a report to the developer.

\section{France}

The implementation of the pilot in France was similar to that in Australia. Participants included 39 outpatients from 2 centers, comprising 20 from the Paris area hospital, Kremlin Bicetre, and 19 in Saint Nazare, a regional hospital. Before the consultation, a research assistant introduced the study, and patients completed the questionnaires using a tablet or computer before consulting the doctor. Comments from this observation process and from participants were noted and synthesized.

\section{Results}

\section{Stage 1: Design and Testing of the Initial Prototype Sociodemographic Data}

The sociodemographic background of the patient participants in France and Australia included in the study were different. The participants in Australia were predominantly White men, whereas $42 \%$ (10/24) of the participants in France were women, and in general, were more culturally and linguistically diverse, with 67\% (16/24) from the African continent. All participants completed at least secondary level education.

\section{Acceptability of the Concept: Patients' Perspectives of Using Digital Health Technology}

\section{French Participants}

Semidirected interviews were conducted with 24 patients in France, of which $92 \%$ (22/24) owned a computer, a third used a tablet, and half possessed smartphones. These interviews included 12 participants who had not seen the application and an additional 12 who reviewed the application after a demonstration using the wireframes to explain the features, by the researcher.

The use of mHealth and digital information sources among these respondents consisted mainly of fitness trackers, government services, and HIV information or news sites. Discussions included the concept of using mHealth devices to communicate HRQL issues with their doctors. Although 75\% (18/24) of patients foresaw advantages to the application as described to them, the other $25 \%(6 / 24)$ could not see the point of using technology in place of face-to-face communication. Some respondents liked the idea of being able to contact their doctors directly, especially in an emergency, and 17\% (4/24) did this through email. Others saw opportunities for the application to act as a reminder, thus focusing the consultation on the topics important to them. For example, one patient stated, "Sometimes when we meet, we do not remember what we wanted to say." Another respondent thought it would strengthen engagement between doctor and patient:

\section{In the health domain it will be a good tool...will bring patients closer to their doctors, it's great...}

However, for some participants, an mHealth evaluation of quality of life was not of particular value. One participant stated the following:

\section{I do not see any utility, I am already followed, I have already been HIV positive for several years and I do the things (sic) well, it is well controlled. I have an appointment every six months. During the six months I do not see any usefulness of an application.}

Some patients thought that the volume of data generated would overload their doctors and reduce the consultation time available for personal conversation. With regard to confidentiality, one patient described himself as "suspicious" of "these types of things." An overriding concern for 45\% (11/24) of French participants, particularly those with migrant backgrounds, was data security and confidentiality. One participant stated as follows:

\section{You do not know to whom you can share all your life, you spread all your life like that; after you do not know who can recover this..., all that is not necessarily good.}

The concern was that their information would be used in newspapers, and they would be identified and exposed to stigma and discrimination, or that information would be revealed if devices were lost. Our conclusion from this round of testing was that patients' acceptance of a potential digital health care communication pathway in France was low.

\section{Australian Participants}

In Australia, 4 in-depth interviews were conducted. The comments of the participants before being shown the prototype application were similar to those of the French participants but reflected more optimism about eHealth services and less concern about confidentiality. In contrast to French participants, Australian participants used the prototype application and progressed through a series of questions drawn from the HRQL questionnaire. The screen design was minimal, showing one question per screen, and was accompanied by a peaceful soundtrack. The participants' feedback after using the software was largely positive, and participants envisaged that doctors would have a better picture of their patients' current health state if the information derived from the HRQL instrument was actively engaged with during the consultation; here, the caveat was how the general practitioner interpreted the patient information. There was a perception that digital communication in health was inevitable with one patient stating as follows: 
I think it is good...The whole world works on technology, so the medical system may as well.

Another patient foresaw benefits to discourse within a prescribed timeframe: "It would be good for the software to be able to let me answer at my home at my own pace and [information] would be shared with my doctor." However, one patient commented as follows:

\section{$O K$, so you can get a prompt current reply with the technology, you don't have to make an appointment to see a doctor, you can get it via technology.}

The patient perceived this as a disadvantage that would potentially complicate his care, but the comment also suggested that the patient envisaged an electronic response from the doctor, rather than unidirectional communication, which was used to enhance face-to-face communication. Another patient considered his future clinical care:

I think for me, because I'm young and I don't have a lot of effects from it [HIV] yet. I guess as I get older, I'm probably going to have more effects, so it's able to keep a really good record of the effects on me, and the doctors always having that record, because it's technology-based, it's never going to go missing.

In contrast to French participants, concern about confidentiality among Australian participants was low. However, one participant would not complete the sensitive information on a portable device when the screen was visible to others. Vulnerability to hacking was also a concern, with a participant stating as follows:

It's not so much you using the data or me giving the data to you...but if you're ever hacked.

However, another participant said as follows:

No, I am not worried, I think confidentiality, like all software, is the same as on paper. You know if anyone wants to get into your documentation they need your passwords or something like that, so, it's capable of doing that nowadays, if you're doing banking and everything...

\section{Design and Usability}

The Australian group provided further detailed feedback about the design and usability of the software, commenting on the mouse versus touch screen and the navigation icons and their likes and dislikes. Consequently, the developer improved the product, removed the soundtrack, and added a privacy statement concerning the level of data encryption provided in the application.

\section{Clinicians' Perspectives: France and Australia}

We deduced from our interviews with clinicians (12 in France and 4 in Australia) that three key design features were important. First, the PRO instrument chosen should be valid and disease specific. Second, it could be used to record and monitor outcomes of interventions and the impacts of the disease process. Finally, the application should be frictionless and integrated with the flow of communication between patient and clinician, as well as with other programs used simultaneously, which may require screen switching.

Younger clinicians had a more positive view of the potential use of mHealth applications than their older colleagues, and they valued digital clinical support software (eg, for prescribing medications). One doctor actively promoted mHealth apps to his patients for self-monitoring and motivational feedback. They also expressed interest in programs to increase retention and continuity of care, thus agreeing with the patient participants' views on the application. One doctor said the following:

The benefit is certain...Because HIV patients are particular, [HIV] always has an impact on their lives, whether it is social or quality of life.

The 4 Australian doctors envisaged how it might be useful for chronic HIV management, as managed by nurses. They recognized the potential for integrating features to support the monitoring of treatment adherence and healthy lifestyle assessments (eg, drug and alcohol use).

\section{Overwhelmed With Information}

In general, doctors were concerned about information overload, with numerous complex concerns becoming difficult to address in the consultation time available. One doctor said, “...the data (for PROs) may be too complex for the average practitioner to interpret" and that, "an amateur assessment of exercise, for example, may not be better than no assessment of exercise."

This clinician articulated that "doctors feel like they need to fix things," implying that PROs might present them with information that could not be adequately actioned, leading to an unsatisfactory outcome for the patient. Another doctor said as follows:

\section{It [the software] has to provide me with a reasonable summary of what is going on without taking 15 minutes to digest it. Otherwise, it just gets too much, does it provide value?...and people will not get through their work, and they will just ignore it.}

French hospital-based doctors stressed that the time available within their consultations to review HRQL via a software application was extremely limited. In primary care, doctors tend to work within purpose-built IT systems for general practice. These programs often contain short questionnaires, such as an alcohol assessment; however, in hospitals, there is a pressing need for an integrated system of IT programs. One doctor stated as follows:

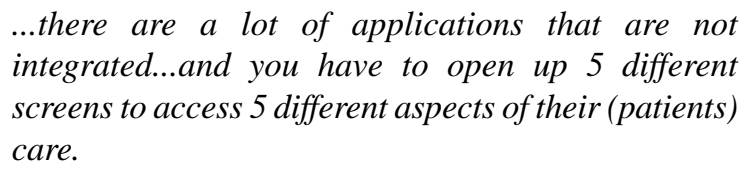

After seeing a representation of the doctors' interface, the 3 primary care clinicians noted the utility of having patient-reported HRQL synthesized and particular items flagged for attention, thus saving time and facilitating what one doctor described as "a better structure to the consultation." One doctor noted that the software could benefit patients with memory problems. 


\section{Patient Safety}

One of the hospital-based clinicians was less convinced of the value of the software for individual patient care because patients' queries are triaged by nurses, whereas in the primary care setting, communication is largely within the consultation and triaged by the doctor. Consequently, one doctor said, "it is very important for the patients not to consider that by pressing 'send' they are directly communicating urgently to the doctor." Clinicians placed emphasis on the need to manage patient expectations and the necessity for clinician training to use and interpret PRO data, so that it can be actioned appropriately.

\section{Confidentiality}

In France, doctors were more likely to address the issue of data security rather than patient confidentiality. They considered absolute security as a critical element of the application. Doctors mentioned several potential risks related to the use of such an application, namely data storage on mobile devices, data submission via the internet, and data security in hospital servers.

\section{Clinicians' Interface}

The clinicians' interface (Figure 3) addresses concerns about the volume of granular information generated by PRO instruments. We used the HRQL questionnaire to illustrate the function of the display for PRO data. Briefly, the items displayed on the screen are color-coded to each response (rarely, sometimes, always, etc), with the color red indicating patient concern to emphasize the report as patient-driven. Accordingly, a sidebar checkbox allows the doctor to indicate that a discussion has taken place. Sections pertaining to physical, emotional, and social health dimensions are displayed as graphs to enable the visualization of changes in health dimension scores over time.

Figure 3. Clinicians' interface.

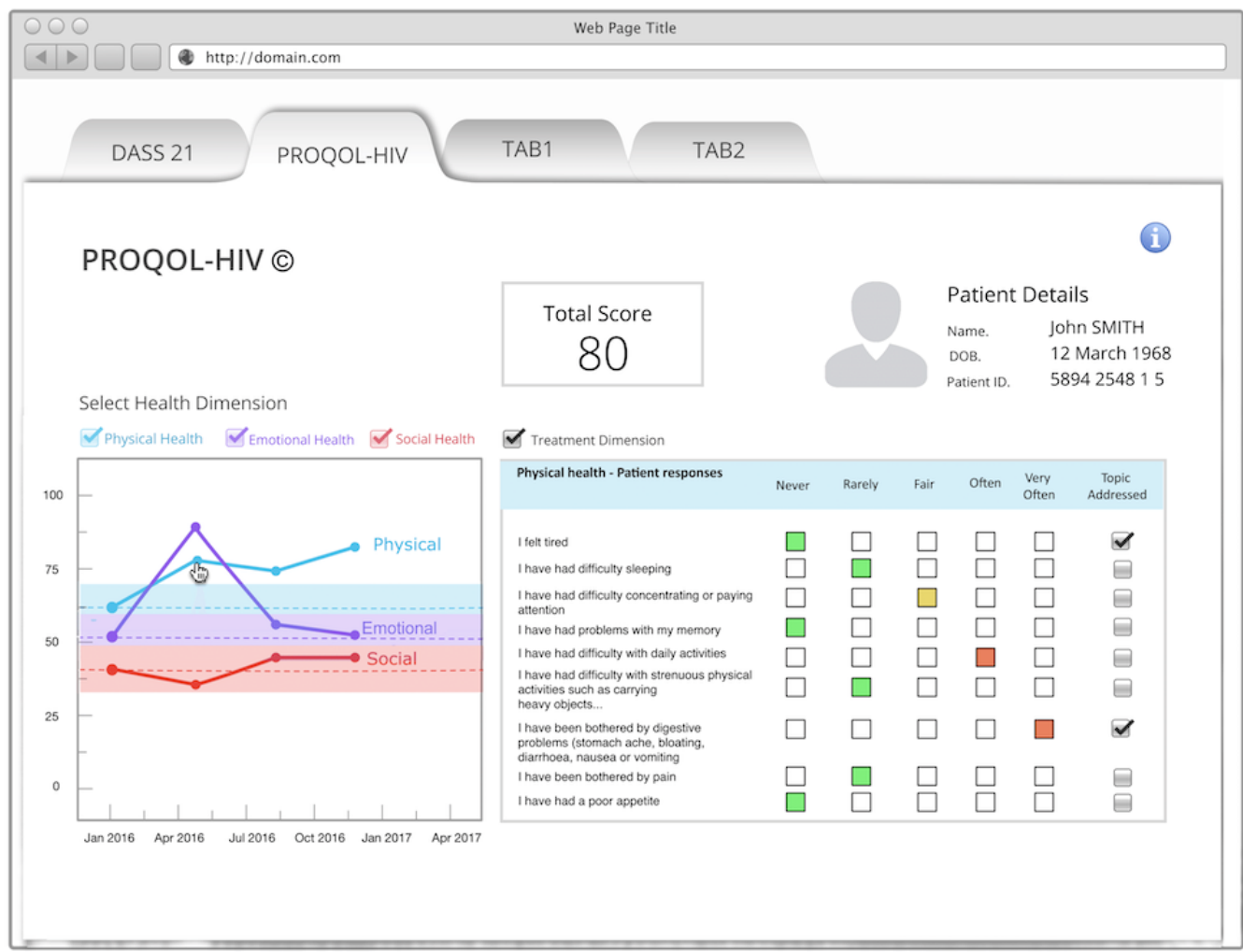

\section{Stage 2: Results of the Pilot Studies in Australia and France}

Table 1 shows the characteristics of patient participants in the pilot study. The average age of Australian patients was 57 years and 90\% (37/41) were men, and HIV transmission was largely sexual reflecting the demographic of the Australian HIV epidemic [26]. The results of the usability testing (Table 2) showed that $98 \%(40 / 41)$ of the participants found the application easy to use, and $61 \%(25 / 41)$ comprehended it quickly. We also observed that older age was associated with reduced scores for understanding the visual interface $(P=.004)$ and finding the buttons organized $(P=.02)$. Furthermore, 24\% (10/41) of respondents were concerned with confidentiality, and this result was more prevalent in participants with higher anxiety and stress scores, as measured by the DASS inventory ( $P=.007$ and $P=.01$, respectively).

The French pilot patient participants' median age was 53 years; they were mostly men and more often single. Usability testing was completed by 19 participants. The results were similar to that of Australian participants regarding ease of use and quick comprehension; however, the French participants were more concerned about confidentiality $(9 / 19,47 \%)$ than the Australian participants. However, for the 15 patients who completed the usability questionnaire and the DASS, the correlation between confidentiality and anxiety and stress scores measured by the DASS inventory was not significant $(r=0.37 ; P=.17)$. The association between older Australians and concern about the organization and function of the application was not tested in the French participants because most French participants had 
assigned a maximum score to those items, creating a ceiling effect.

The commentary received from the French patients was largely positive for all aspects of the application design. Overall, patients reported being glad to identify topics that they would not usually or spontaneously discuss with their clinician, and this opportunity could incentivize them to use the application over a longer period. A concern was raised that standardization via the use of questionnaires may threaten individualized care and not take into consideration individual circumstances. For doctors, an annoyance was the necessity to open another software application on their screen, in addition to the patient record.

Table 1. Characteristics of patients in the pilot study $(\mathrm{N}=80)$.

\begin{tabular}{|c|c|c|c|c|}
\hline \multirow[t]{2}{*}{ Characteristics } & \multicolumn{2}{|c|}{ Australian patients } & \multicolumn{2}{|c|}{ French patients } \\
\hline & Total, n (\%) & Value & Total, n (\%) & Value \\
\hline \multicolumn{5}{|l|}{ Demographics, median (range) } \\
\hline Age (years) & $41(51)$ & $58(50-64)$ & $39(49)$ & $52(44-60)$ \\
\hline Duration HIV (months) & $34(43)$ & $228(153-312)$ & $36(45)$ & $126(69-240)$ \\
\hline Sex, $n(\%)$ & $41(51)$ & & $36(45)$ & \\
\hline Male & & $37(90)$ & & $29(81)$ \\
\hline Female & & $4(10)$ & & $7(19)$ \\
\hline Ethnicity, n (\%) & $38(48)$ & & $36(45)$ & \\
\hline White & & $33(87)$ & & $27(75)$ \\
\hline Asian & & $4(10)$ & & $1(3)$ \\
\hline Middle Eastern & & $1(3)$ & & $0(0)$ \\
\hline African & & $0(0)$ & & $7(19)$ \\
\hline Latinx & & $0(0)$ & & $1(3)$ \\
\hline Mode of transmission, $n(\%)$ & $33(41)$ & & $36(45)$ & \\
\hline $\mathrm{MSM}^{\mathrm{a}}$ & & $27(82)$ & & $22(61)$ \\
\hline Heterosexual & & $6(18)$ & & $14(39)$ \\
\hline Employment, n (\%) & $41(51)$ & & $19(34)$ & \\
\hline Employed & & $23(56)$ & & $12(63)$ \\
\hline Not employed & & $18(44)$ & & $7(37)$ \\
\hline \multicolumn{5}{|l|}{ Clinical variables } \\
\hline CD4 T cells, median (range) & $31(39)$ & $703(458-946)$ & $36(45)$ & $610(480-872)$ \\
\hline \multicolumn{5}{|l|}{ HIV viral load, n (\%) } \\
\hline$>20$ copies $/ \mathrm{ml}$ & $31(39)$ & $\mathrm{N} / \mathrm{A}^{\mathrm{b}}$ & $33(41)$ & $33(92)$ \\
\hline$<20$ copies $/ \mathrm{ml}$ & $31(39)$ & $31(100)$ & $3(4)$ & $3(8)$ \\
\hline HBV-HCV coinfection, $\mathrm{n}(\%)$ & $31(39)$ & $0(0)$ & $35(44)$ & $10(29)$ \\
\hline
\end{tabular}

${ }^{a}$ MSM: men who have sex with men.

${ }^{b}$ N/A: Not applicable. 
Table 2. Pilot study usability testing ${ }^{\mathrm{a}}(\mathrm{N}=60)$.

\begin{tabular}{|c|c|c|}
\hline Response $^{b}$ & Australian $(\mathrm{n}=41), \mathrm{n}(\%)$ & French $(n=19), n(\%)$ \\
\hline Easy to use & $40(98)$ & $18(95)$ \\
\hline I would need support to use it & $0(0)$ & $3(16)$ \\
\hline I would use it again & $41(100)$ & $16(84)$ \\
\hline Had a clear, clean design & $40(98)$ & $18(95)$ \\
\hline Required minimum screen changes & $41(100)$ & $\mathrm{N} / \mathrm{A}^{\mathrm{c}}$ \\
\hline I found it easy and quick to comprehend & $25(61)$ & $18(95)$ \\
\hline The instructions were clear and unambiguous & $37(90)$ & $17(90)$ \\
\hline The buttons organized and easy to find & $35(85)$ & $19(100)$ \\
\hline I understood the function & $28(68)$ & $19(100)$ \\
\hline I found it easy to navigate & $40(98)$ & $19(100)$ \\
\hline The size, style, and font were appropriate & $39(95)$ & N/A \\
\hline It was a pleasant experience & $38(93)$ & $17(90)$ \\
\hline I found it intuitive to use & $31(76)$ & $15(79)$ \\
\hline I was concerned about confidentiality & $10(24)$ & $9(47)$ \\
\hline
\end{tabular}

${ }^{\text {a} P i l o t ~ t e s t ~ w a s ~ c a r r i e d ~ o u t ~ i n ~ a ~ p r i m a r y ~ h e a l t h ~ c a r e ~ s e t t i n g ~(A u s t r a l i a) ~ a n d ~ a ~ h o s p i t a l-b a s e d ~ s e t t i n g ~(F r a n c e) . ~}$

besponses to the questionnaire item "The application was judged to be."

${ }^{\mathrm{c}}$ N/A: Not applicable (two items were not asked of French participants).

\section{Discussion}

\section{Principal Findings}

We designed and tested a software application enabling the transfer of PRO from a user's device to a clinician's electronic patient management system through a secure portal. A key capability is the display of synthesized data with the potential to focus patient and doctor discourse on patient-driven information; the data are measurable and can be mapped against the implementation of interventions (ie, action points). The design permits the prioritization of actions between visits, further supporting patient preference, and the use of validated instruments could accommodate concerns about the consistency and reliability of repeated PRO results. As the software is configurable, validated PRO instruments can be selected based on clinical requirements (eg, a questionnaire for monitoring side effects or adherence to a new medication). The use of ePRO measures is becoming commonplace and acceptable with some caveats [27]. Our methods enabled us to integrate users' opinions on the application design and increase the validity of the product [28] and its visual appeal. The design is a combination of function and form, as it is esthetically pleasing. However, by taking a minimal approach to the software design, we maximized the potential of the product to meet the needs of the end user and prevent "overspecification." Although we found that older age was associated with reduced scores for some aspects of usability, none of the patients in the pilot study indicated that they would need support to use the application again.

Data from the predesign phase indicated interest in enhanced patient-doctor communication, supported by mHealth strategies, although a few patients considered it unnecessary. Hitherto, most participants had only thought of mHealth in terms of health monitoring and fitness applications. There was initial confusion regarding what form the flow of information would take and what feedback, if any, they would receive from their doctors. The French patients considered feedback important and expected results or a score. The Australian patients were more concerned about how the doctor would use this information and whether it would improve their care in the long term. In general, participants envisaged an efficiency gain for themselves, and the doctors, if the volume of data transmitted was not overwhelming. The idea of entering data at home in preparation for their medical consult fits with their practice of a preappointment blood test, whereby the results would be ready for discussion on arrival. In both countries, electronic transmission of laboratory results to medical practice software and linkage with the patient's file is common. Confidentiality and data security were major concerns among French patients, particularly migrants, and doctors. Such concerns were less striking among Australian interviewees who had confidence in data protection processes. However, the results of the Australian pilot study revealed that participants with high stress and anxiety scores as measured by the DASS tended to worry about confidentiality when entering their own health information in actuality, as opposed to a hypothetical situation, and this was true of the French participants as well. Evidence also showed that participants perceived greater privacy in using the application on a computer in their own home, in contrast to using the application on a mobile device in public. Notwithstanding, people with stigmatized illnesses are significantly more likely to use the internet to communicate with clinicians [29]. 


\section{Strengths and Limitations of the Study}

We conducted our study in a primary care context in Australia and a hospital-based setting in France. Although this is a strength in the context of product development, it has implications for the design of randomized controlled trials and the subsequent implementation of PRO measures in clinical care [30,31]. We tested our software in the context of HIV care, but we believe our findings are equally useful for other chronic illnesses. Both countries offer free universal health care; however, in Australia, primary care is fee for service and government rebates rarely cover the cost of a consultation, which varies according to length. Public hospital care is free, but clinics are busy and there is an incentive for shorter consultations. The use of eHealth software to support the integration of PRO could reduce the number of doctor visits, as reported by Kjaer et al [10] without compromising patient care. In addition, for web-based platforms used in health settings and within most practice, software has the ability to import data from other programs via interoperable formats such as XML. We achieved this using REDCap as a proxy for practice software. This served as a good test case for import and export functionalities, and the software was designed so that developing and plugging export adaptors for specific and proprietary clinical software packages is possible.

Our software was tested in a research environment, and although the esthetics were carefully considered to make it pleasurable to use, we do not know if patients will experience software fatigue over time, as is evidenced by the large number of mobile apps that have been designed [32]. However, we believe that a design that facilitates an experience that feels personal, in contrast with a well-constructed but impersonal form, will influence a patient's perception of the quality of care they receive in the absence of direct contact; this will be advantageous for people living in rural and remote settings. Our participants were largely computer literate, which may affect the generalizability of the product suitability for other demographic groups. In addition, some might express concern that variation in the mode of delivery might affect responses; however, research has found that when sampling protocols are followed, data equivalence can be achieved, although this research came with caveats [33]. The doctors also showed interest in using the software; however, further work will be necessary, as well as education and training on the utility of PRO data per se for patient care, as has been flagged by others $[27,34]$. A systematic review of mHealth adoption by Gagnon et al [35] found that utility and ease of use were two of the most important factors influencing uptake by health care professionals, and more recent reviews [30] reported organizational factors that must be considered. However, these factors vary according to the context.

\section{Conclusions}

We recognize that to be an effective tool and to provide clear value, the therapeutic benefit of using this application needs to be evident to doctors and patients [16]. This could be considered both a strength and a weakness of our design; however, the concept of the therapeutic relationship between clinician and patient underpins our design. For example, interaction with the doctor during the consultation could motivate the patient to input PRO data at home in preparation for the next visit, and equally, the clinical return achieved will motivate the doctor to use the software repeatedly. We also see the potential for the integration of a range of PRO instruments in a single platform, not only confined to the management of HIV infection, including, for example, side-effect questionnaires. These could help quantify the qualitative impacts of pharmaceutical interventions in tandem with medication adherence between visits. To establish the utility of this application, we envisage that a randomized controlled trial design, informed by an implementation strategy and coupled with a qualitative analysis evaluating the software over an extended period, will be necessary.

\section{Acknowledgments}

We are grateful to the participants of this study for their time and effort contributing to the research and the final product. We also thank our colleagues from the following institutions: In Western Australia: The Institute for Immunology and Infectious Diseases at Murdoch University: Mina John, Ian Bradley, Paul Egan, Ramesh Ram, Maeve Berry; and GP on Beaufort in Mt Lawley (Belinda Wozencroft, Fergus McCabe, Ric Chaney. In France: URC ECO, PRO Unit AP-HP: AP-HP: Christophe Lalanne, Jim Jouannigot, Lihui XU, Olivier Chassany, Pascal Bessonneau, Pierre Sarrot; Hôpital de Kremlin Bicetre: Cécile Goujard, Yann Quertainmont, Françoise Chouraqui, Centre Hospitalier Saint Nazaire: Nathalie Pouhaut, Carole Grand-Courault; L'Institut Mutualiste Montsouris: Loic Bodard, Hospital Lariboisiere: Agathe Rami. This work was supported by a GILEAD Sciences Europe Limited goSHAPE grant.

\section{Conflicts of Interest}

None declared.

\section{Multimedia Appendix 1}

Moodboard.

[DOCX File, 1159 KB-Multimedia Appendix 1]

\section{References}


1. Herrmann S, McKinnon E, Hyland NB, Lalanne C, Mallal S, Nolan D, et al. HIV-related stigma and physical symptoms have a persistent influence on health-related quality of life in Australians with HIV infection. Health Qual Life Outcomes 2013 Apr 08;11(1):56 [FREE Full text] [doi: 10.1186/1477-7525-11-56] [Medline: 23566318]

2. Chan EK, Edwards TC, Haywood K, Mikles SP, Newton L. Implementing patient-reported outcome measures in clinical practice: a companion guide to the ISOQOL user's guide. Qual Life Res 2019 Mar 17;28(3):621-627 [FREE Full text] [doi: 10.1007/s11136-018-2048-4] [Medline: 30448911]

3. Snyder CF, Aaronson NK, Choucair AK, Elliott TE, Greenhalgh J, Halyard MY, et al. Implementing patient-reported outcomes assessment in clinical practice: a review of the options and considerations. Qual Life Res 2012 Oct;21(8):1305-1314. [doi: 10.1007/s11136-011-0054-x] [Medline: 22048932]

4. Austin E, LeRouge C, Hartzler AL, Segal C, Lavallee DC. Capturing the patient voice: implementing patient-reported outcomes across the health system. Qual Life Res 2020 Feb 12;29(2):347-355 [FREE Full text] [doi:

10.1007/s11136-019-02320-8] [Medline: $\underline{\text { 31606809] }}$

5. Snyder CF, Blackford AL, Wolff AC, Carducci MA, Herman JM, Wu AW, PatientViewpoint Scientific Advisory Board. Feasibility and value of PatientViewpoint: a web system for patient-reported outcomes assessment in clinical practice. Psychooncology 2013 Apr;22(4):895-901 [FREE Full text] [doi: 10.1002/pon.3087] [Medline: 22544513]

6. Holzner B, Giesinger JM, Pinggera J, Zugal S, Schöpf F, Oberguggenberger AS, et al. The Computer-based Health Evaluation Software (CHES): a software for electronic patient-reported outcome monitoring. BMC Med Inform Decis Mak 2012 Nov 09;12(1):126 [ [FREE Full text] [doi: 10.1186/1472-6947-12-126] [Medline: 23140270]

7. Muessig KE, Nekkanti M, Bauermeister J, Bull S, Hightow-Weidman LB. A systematic review of recent smartphone, internet and web 2.0 interventions to address the HIV continuum of care. Curr HIV/AIDS Rep 2015 Mar;12(1):173-190 [FREE Full text] [doi: 10.1007/s11904-014-0239-3] [Medline: 25626718]

8. WHO Global Observatory for eHealth. mHealth: new horizons for health through mobile technologies: second global survey on eHealth. In: World Health Organisation 2019. URL: https://apps.who.int/iris/handle/10665/44607 [accessed 2021-07-27]

9. Wintner LM, Giesinger JM, Zabernigg A, Rumpold G, Sztankay M, Oberguggenberger AS, et al. Evaluation of electronic patient-reported outcome assessment with cancer patients in the hospital and at home. BMC Med Inform Decis Mak 2015 Dec 23;15(1):110 [FREE Full text] [doi: 10.1186/s12911-015-0230-y] [Medline: 26699708]

10. Kjær AS, Rasmussen TA, Hjollund NH, Rodkjaer LO, Storgaard M. Patient-reported outcomes in daily clinical practise in HIV outpatient care. Int J Infect Dis 2018 Apr;69:108-114 [FREE Full text] [doi: 10.1016/j.ijid.2018.02.015] [Medline: 29476900]

11. Schougaard LM, Larsen LP, Jessen A, Sidenius P, Dorflinger L, de TA, et al. AmbuFlex: tele-patient-reported outcomes (telePRO) as the basis for follow-up in chronic and malignant diseases. Qual Life Res 2016 Mar;25(3):525-534 [FREE Full text] [doi: 10.1007/s11136-015-1207-0] [Medline: 26790427]

12. Scotté F, Minvielle E, Mir O, André F, Barlesi F, Soria J. A patient reported outcome platform, a useful tool to improve monitoring and effective management of Covid-19-positive patients with cancer. Eur J Cancer 2020 Jun;132:1-4 [FREE Full text] [doi: 10.1016/j.ejca.2020.03.020] [Medline: 32294611]

13. Fredericksen R, Crane PK, Tufano J, Ralston J, Schmidt S, Brown T, et al. Integrating a web-based, patient-administered assessment into primary care for HIV-infected adults. J AIDS HIV Res 2012 Feb;4(2):47-55 [FREE Full text] [doi: 10.5897/jahr11.046] [Medline: 26561537]

14. Alyahya S, Ivins WK, Gray WA. Raising the awareness of development progress in distributed agile projects. J Software 2013 Dec 01;8(12):3066-3081. [doi: 10.4304/jsw.8.12.3066-3081]

15. Shore J, Warden S. The Art of Agile Development: Pragmatic Guide to Agile Software Development. Sebastopol, California: O'Reilly Media Inc; 2007.

16. Steele GC, Khan AI, Kuluski K, McKillop I, Sharpe S, Bierman AS, et al. Improving patient experience and primary care quality for patients with complex chronic disease using the electronic patient-reported outcomes tool: adopting qualitative methods into a user-centered design approach. JMIR Res Protoc 2016 Feb;5(1):e28 [FREE Full text] [doi:

10.2196/resprot.5204] [Medline: 26892952]

17. Lovibond S, Lovibond P. Manual for the Depression Anxiety Stress Scales. 2nd Ed. Sydney: Psychology Foundation; 1995.

18. Duracinsky M, Herrmann S, Berzins B, Armstrong A, Kohli R, Le Coeur S, et al. The development of PROQOL-HIV: an international instrument to assess the health-related quality of life of persons living with HIV/AIDS. J Acquir Immune Defic Syndr 2012 Apr 15;59(5):498-505. [doi: 10.1097/QAI.0b013e318245cafe] [Medline: 22205438]

19. Braun V, Clarke V. Using thematic analysis in psychology. Qual Res Psychol 2006 Jan;3(2):77-101. [doi: 10.1191/1478088706qp063oa]

20. Guest G, Bunce A, Johnson L. How many interviews are enough? Field Methods 2016 Jul 21;18(1):59-82. [doi: $10.1177 / 1525822 \mathrm{X} 05279903]$

21. Harris PA, Taylor R, Thielke R, Payne J, Gonzalez N, Conde JG. Research electronic data capture (REDCap)--a metadata-driven methodology and workflow process for providing translational research informatics support. J Biomed Inform 2009 Apr;42(2):377-381 [FREE Full text] [doi: 10.1016/j.jbi.2008.08.010] [Medline: 18929686]

22. The R Project for statistical computing. R Foundation for Statistical Computing, Vienna, Austria. URL: https://www. R-project.org/ [accessed 2021-07-09] 
23. Shaffer E, Lahiri A. The Institutionalization of UX: A Step-by-Step Guide to a User Experience Practice. 2nd Ed. Upper Saddle River, New Jersey: Addison-Wesley; 2014.

24. Duracinsky M, Jouannigot J, Grace A, Power B, Desai R, Lalanne C, et al. Acceptability of electronic patient reported outcomes in clinical care of HIV. Value in Health 2016 Nov;19(7):A702. [doi: 10.1016/j.jval.2016.09.2040]

25. Duracinsky M, Lalanne C, Goujard C, Herrmann S, Cheung-Lung C, Brosseau J, et al. Electronic versus paper-based assessment of health-related quality of life specific to HIV disease: reliability study of the PROQOL-HIV questionnaire. J Med Internet Res 2014 Apr 25;16(4):e115 [FREE Full text] [doi: 10.2196/jmir.3330] [Medline: 24769643]

26. National Update on HIV, Viral Hepatitis and Sexually Transmissible Infections in Australia: 2009-2018. Sydney, NSW: The Kirby Institute for Infection and Immunity in Society; 2020:1-36.

27. Fredericksen RJ, Fitzsimmons E, Gibbons LE, Loo S, Dougherty S, Avendano-Soto S, et al. How do treatment priorities differ between patients in HIV care and their providers? A mixed-methods study. AIDS Behav 2020 Apr 12;24(4):1170-1180 [FREE Full text] [doi: 10.1007/s10461-019-02746-8] [Medline: 31832854]

28. Nielsen J. 10 usability heuristics for user interface design. Nielsen Norman Group. 1994. URL: https://www.nngroup.com/ articles/ten-usability-heuristics [accessed 2021-05-18]

29. Berger M, Wagner TH, Baker LC. Internet use and stigmatized illness. Soc Sci Med 2005 Oct;61(8):1821-1827. [doi: 10.1016/j.socscimed.2005.03.025] [Medline: 16029778]

30. Foster A, Croot L, Brazier J, Harris J, O'Cathain A. The facilitators and barriers to implementing patient reported outcome measures in organisations delivering health related services: a systematic review of reviews. J Patient Rep Outcomes 2018 Dec 3;2(1):46 [FREE Full text] [doi: 10.1186/s41687-018-0072-3] [Medline: 30363333]

31. Roberts NA, Alexander K, Wyld D, Janda M. Factors in randomized controlled trials reported to impact the implementation of patient-reported outcome measures into routine care: protocol for a systematic review. JMIR Res Protoc 2019 Nov 26;8(11):e14579 [FREE Full text] [doi: 10.2196/14579] [Medline: 31769763]

32. Boulos MN, Brewer AC, Karimkhani C, Buller DB, Dellavalle RP. Mobile medical and health apps: state of the art, concerns, regulatory control and certification. Online J Public Health Inform 2014 Feb;5(3):229 [FREE Full text] [doi: 10.5210/ojphi.v5i3.4814] [Medline: 24683442]

33. Belisario JS, Jamsek J, Huckvale K, O'Donoghue J, Morrison C, Car J. Comparison of self-administered survey questionnaire responses collected using mobile apps versus other methods. Cochrane Database Syst Rev 2015 Jul 27(7):MR000042 [FREE Full text] [doi: 10.1002/14651858.MR000042.pub2] [Medline: 26212714]

34. Fredericksen RJ, Tufano J, Ralston J, McReynolds J, Stewart M, Lober WB, et al. Provider perceptions of the value of same-day, electronic patient-reported measures for use in clinical HIV care. AIDS Care 2016 Nov 29;28(11):1428-1433 [FREE Full text] [doi: 10.1080/09540121.2016.1189501] [Medline: 27237187]

35. Gagnon M, Ngangue P, Payne-Gagnon J, Desmartis M. m-Health adoption by healthcare professionals: a systematic review. J Am Med Inform Assoc 2016 Jan;23(1):212-220. [doi: 10.1093/jamia/ocv052] [Medline: 26078410]

\section{Abbreviations}

DASS: Depression, Anxiety and Stress Scale

HRQL: health-related quality of life

IT: information technology

mHealth: mobile health

PRO: patient-reported outcome

PROQOL-HIV: Patient Reported Outcomes Quality of Life-HIV

REDCap: Research Electronic Data Capture

WA: Western Australia

Edited by $R$ Kukafka; submitted 22.02.21; peer-reviewed by S Mikles, I Zimianiti; comments to author 24.03.21; revised version
received $19.05 .21 ;$ accepted $14.06 .21 ;$ published 30.07 .21
Please cite as:
Herrmann S, Power B, Rashidi A, Cypher M, Mastaglia F, Grace A, McKinnon E, Sarrot P, Michau C, Skinner M, Desai R, Duracinsky
Supporting Patient-Clinician Interaction in Chronic HIV Care: Design and Development of a Patient-Reported Outcomes Software
Application
J Med Internet Res $2021 ; 23(7): e 27861$
URL: $\underline{\text { https://www.jmir.org/2021/7/e27861 }}$
doi: $\underline{10.2196 / 27861}$
PMID: $\underline{34328442}$


(CSusan Herrmann, Brad Power, Amineh Rashidi, Mark Cypher, Frank Mastaglia, Amy Grace, Elizabeth McKinnon, Pierre Sarrot, Christophe Michau, Matthew Skinner, Renae Desai, Martin Duracinsky. Originally published in the Journal of Medical Internet Research (https://www.jmir.org), 30.07.2021. This is an open-access article distributed under the terms of the Creative Commons Attribution License (https://creativecommons.org/licenses/by/4.0/), which permits unrestricted use, distribution, and reproduction in any medium, provided the original work, first published in the Journal of Medical Internet Research, is properly cited. The complete bibliographic information, a link to the original publication on https://www.jmir.org/, as well as this copyright and license information must be included. 